\title{
Telecommunication Power System: energy saving, renewable sources and environmental monitoring
}

\author{
Carmine Lubritto \\ Department of Environmental Science, \\ II University of Naples \\ ITALY
}

\section{Introduction}

The considerable problems deriving from the growth of energetic consumptions and from the relevant environmental "emergency" due to the emissions of greenhouse gases, push people to find out new solutions and new technologies for the production of primary energy fit for fulfilling the urging and growing energetic demands.

The global climate change, which is due to increased $\mathrm{CO}_{2}$ and other green house gases concentration levels in atmosphere, is considered one of the most important global emergency that requires immediate and effective policies (IPCC,2007). The $\mathrm{CO}_{2}$ emissions are mostly due to the use of fossil fuels as energy source. Thus in the future the use of fossil fuels has to be decreased. This can be obtained by improving energy efficiency and by using large scale renewable energy sources.

This is also true in the telecommunication applications, which has seen, in the last years, a remarkable increase in the number of installations present on the whole territory sometimes located in hardly reachable areas - and the relevant growth of energetic consumptions, because of growing interest about new and reliable services in mobility calls with an increase of the BTS operation hours and traffic management, in order to guarantee the quality of the service anywhere and anytime.

As an example, in the last years the development of the telecommunications sector has resulted in a significant increase of the number of Base Transceiver Station (BTS) on the Italian territory: according to the official database of the non ionizing radiation observatory of the National Agency for Environment (ISPRA,2007), the BTS present in Italy are about 60.000. On the other hand it has been shown (Roy, 2008) that the energetic consumptions of a typical operator network varies between 1.5 TWh to 9 TWh for a year. What is alarming is what we are faced in the future. On the wired line side it is expected a relevant growth of the number of broadband subscribers with a power per subscriber rate that is 4 to 8 times the traditional consumption, while on the wireless side the number of connected device with high speed data services is growing. By extrapolation, it has been estimated (Roy, 2008) that the telecom industry consumed last year about $1 \%$ of the global energy consumption of the 
planet, that is the equivalent energy consumption of 15 million US homes and also the equivalent $\mathrm{CO} 2$ emissions of 29 million cars.

Therefore, the reduction of the energetic consumptions of a Telecommunications Power Systems represents one of the critical factors of the telecommunication's technologies, both to allow a sizeable saving of economic resources to the mobile communications system management and to realize "sustainable" development actions. In other words improving the energy efficiency of telecom networks is not just a necessary contribution towards the fight against global warming, but with the rapidly rising prices of energy, it is becoming also a financial opportunity.

Therefore clear and defined approaches must be taken to optimize actions of energy savings. A telecom network is just like an eco-system: one cannot just apply any energy savings actions without looking at the impacts on the other system components (Roy, 2008). It has been proposed an "Energy Logic Method" which might be applied to both a wireless and a wired line network. This approach is based on a holistic method to energy savings and provides a complete roadmap of recommendations and quantifies their savings, reviewing also the different impacts.

Starting from these considerations the research project "Telecommunication power systems: energy saving, renewable sources and environmental monitoring" was launched by the Department of Environmental Sciences of the Second University of Naples (DSA-SUN) and the Institute for the Environmental Research (ISPRA), with the participation of the Italian suppliers of mobile telecommunications (H3G, Vodafone, Telecom and Wind) and their technological partners (Ericsson).

The general goal of the research project is to study a set of solutions which may allow:

a) to obtain a rationalization of the consumptions of a BTS through the intervention on energy saving;

b) to produce, in the sites where the BTS are located, energy coming from renewable sources - aiming to reduce the emissions of polluting agents in the atmosphere;

c) to implement intelligent monitoring systems for the energy consumptions and the relevant impacts on the environment.

It has been evaluated, from a technical and economical point of view, the feasibility of some solutions , including:

- Energetic auditing for a radio-telecommunication station in different operational contexts (urban and rural areas, different periods in the year, different working load, etc.);

- Interventions of efficiency and energy saving such as reduction of transmission apparatus consumptions, optimization of air conditioning consumptions, efficiency in the temperature control system;

- Evaluation and development of interventions and technical solutions based on the production of a part of the energy used by radio-telecommunication apparatus, through the use of photovoltaic cells on the infrastructures themselves; 
- Analyses of possible uses of other renewable sources (e.g. wind micro turbines) generating energy usable for telecommunication power systems located in areas not reached by the electricity network;

- Analyses of the social and environmental advantages in the introduction of technologies based on renewable sources for covering a part of the energy requirements of radio-telecommunication installations;

- Simulation studies useful to estimate the amount of energy that can be saved using a software system that helps to use the BTS-GSM transmission power in a more efficient way according to the telecommunication traffic features.

- Environmental monitoring of the sites where prototypal solutions has been installed, aimed to compare the conditions before and after the intervention.

\section{Wireless network energy consumption}

The typical wireless network can be viewed as composed by three different sections:

- the Mobile Switching Center (MSC), that take care of switching and interface to fixed network;

- Radio Base Station (RBS), which take care of the frequency interface between network and mobile terminals;

- Mobile terminals, which is the subscriber's part, normally limited to the handheld device.

It is estimated that over $90 \%$ of the wireless network energy consumption is part of the operator's operating expenses (Scheck, 2008).

The key elements are the radio base stations because of the number of base stations is relative high with relative high energy consumption. On the other hand as the number of core network elements is low, the total energy consumption due to core network is relative low. Finally the energy consumption of mobile terminals is very low due to the mobile nature.

With these premises the ways to decrease energy consumptions of cellular network and thus to reduce cost and $\mathrm{CO}_{2}$ emissions are:

- Minimizing BTS energy consumption;

- Use of renewable energy sources.

Moreover could also be considered a minimization of number of BTS sites in order to reduce energy consumption: in this case the network design play an important role to implement a telecom network with correct capacity and minimum number of sites at optimum locations.

The model used in this paper for a a typical Radio Base Station is shown in figure 1. It is the same model analyzed and presented in the literature (Roy,2008; White Paper Ericsson 2007; Lubritto, 2008). Analysing the proposed scheme it result that the system takes $10.3 \mathrm{~kW}$ of electricity to produce only 120 watts of transmitted radio signals and to process the incoming signals from the subscriber cell phones, with a total efficiency (output power/input power) of about $1.2 \%$. 


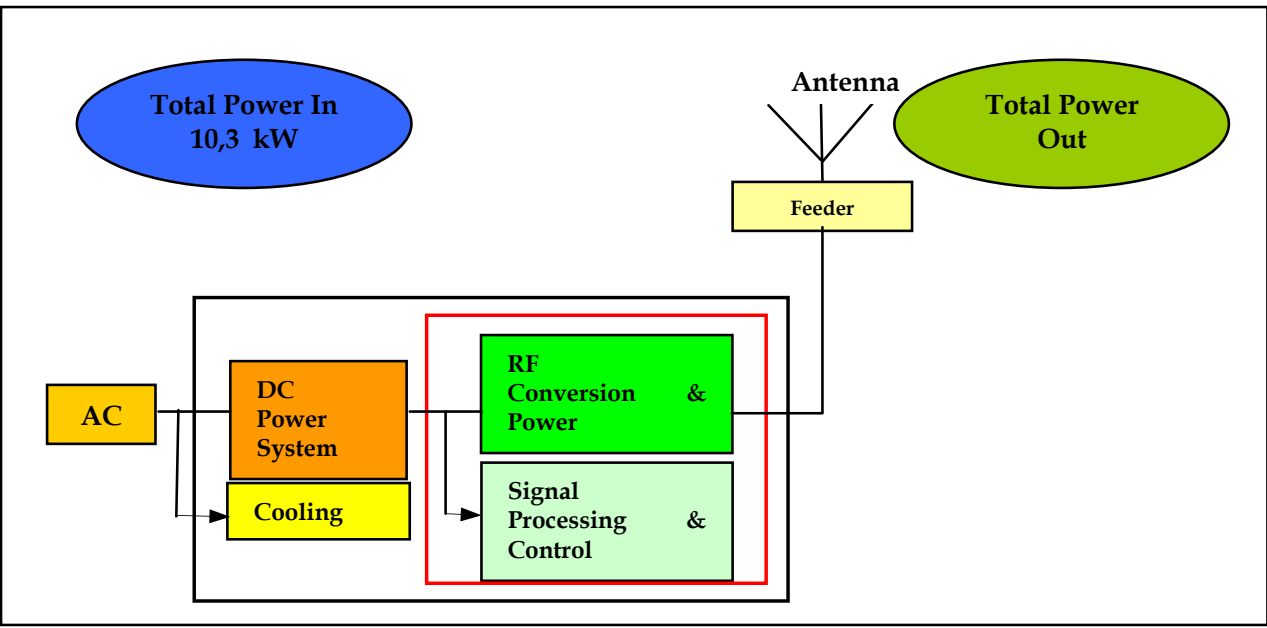

Fig. 1. RBS Block Diagram

In figure 2 is shown the energy allocation per function within the RBS (Roy, 2008). More than $60 \%$ of the power is consumed by the radio equipment and amplifiers, $11 \%$ is consumed by the DC power system and $25 \%$ by the cooling equipment, an air conditioning unit, typical of many such sites. The Radio Equipment and the Cooling are the two major sections where the highest energy savings potential resides.

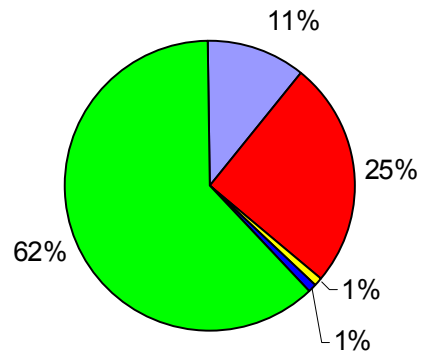

$\square$ DC Power

$\square$ Cooling

$\square$ Load

Feeder

$\square$ Radio Equipment

Fig. 2. Percent BTS Energy per function

In the framework of the energy saving, it is very important to consider a cascade effect that represents in aggregate a benefit of 28 times: for example, saving $1 \mathrm{~W}$ in the feeder cables saves 17.3 watts of modulation and amplification losses, $3.3 \mathrm{~W}$ of rectification losses and 7.1W of associated cooling energy (Roy, 2008). 


\subsection{BTS Energy Savings Strategies}

In the last years many Energy Savings Strategies for Wireless Network, applied both to the radio equipment and to the cooling and power equipment. have been proposed (Roy, 2008, White Paper Ericsson, 2007; Louhi, 2007; Cuccietti, 2006; Lubritto, 2008)

1. Remote Radio Units: consists in moving the RF converters and power amplifiers from the base of the station to the top of the tower close to the antenna and connecting them via fiber cables. This strategy offers the higher potential energy savings: most radio manufacturers now offer this topology.

2 Radio Standby Mode The second strategy is very easy to implement and typically consists of a software and basic hardware upgrade. Often termed ECO Mode or Power Saving Mode, this strategy consists of turning radio transmitters and receivers off when the call traffic goes down, typically during the night. When the ECO Mode is implemented, the power consumption can be reduced by up to $40 \%$ under low traffic. Overall, this strategy will reduce the consumption of the radio equipment between 10 to $20 \%$, plus its associated power conversion and cooling energy requirements. Overall this translates into cascaded savings in the order of 6 to $7 \%$.

3 Passive Cooling The third area of focus is the cooling. Such cooling requires, usually $1 / 3$ of the heat produced inside the RBS. It is also a noisy and maintenance intensive solution. Depending on the geographic location, other cooling techniques such as free ventilation, forced fan cooling with hydrophobic filtering or heat exchangers will change significantly the energy consumption, and often yield a lower total cost of ownership. It is estimated that passive cooling can provide energy savings above $10 \%$.

4 Advanced Climate Control for Air Conditioners If an air conditioner remains necessary, one can minimize its consumption operating at a higher temperature at opportune moments. By doing so, the energy consumption is reduced for two reasons, one that the higher set point means that the unit will be turned on less frequently, and two that it will run more efficiently due to the higher temperature at the air exchange. A total savings of $3-4 \%$ can safely be obtained without major availability impacts.

5 DC Power System ECO Mode The last two strategies relate to the DC power plant. Evidently, at this stage, we have already reduced the load through the previous measures and introduced the radio ECO mode to further reduce the load during low traffic periods. An advanced system controller scheme can ensure that rectifiers will operate at their peak efficiency over virtually all conditions

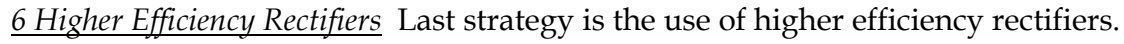

When all strategies are considered, total savings above more than $58 \%$ are possible (Roy,2008):

- On the radio side, going to a Remote Radio concept and applying the Radio ECO functionality will reduce the energy consumption by $40 \%$. 
- On the infrastructure side, the cooling costs can be improved by optimizing the use of the air conditioner or preferably, by migrating to a more passive approach. These will take to down by an additional $3 \%$ and $11 \%$ respectively, cumulatively down by $54 \%$.

- Finally, the last $4 \%$ of reduction will come from the DC plant by implementing energy management to keep the rectifiers at their peak efficiency level and by opting for higher efficiency rectifiers.

In the paragraph 3.2 results of specific studies concerning Radio Standby Mode Strategy will be presented.

\subsection{Renewable energy sources}

As mentioned above a second way to reduce cost and $\mathrm{CO}_{2}$ emissions is the evaluation and development of interventions and technical solutions based on the production of a part of the power energy used by radio-telecommunication apparatus, through the use renewable sources (e.g. photovoltaic cells, wind micro turbines or new alternative power based on fuel cells) installed on the infrastructures themselves or usable from off-grid telecommunications power systems. The use of alternative energy sources has been studied in particular for sites that are beyond the reach of an electricity grid, or where the electricity supply is unreliable or sites remote enough to make the regular maintenance and refueling of diesel generators prohibitive (Morea, 2007; Boccaletti, 2007). The choice of alternative energy source will depend on local conditions, BTS typology and energy consumption.

Solar and wind power can provide virtually free energy. Solar power is a mature technology and can be used for low- and medium capacity sites. Apart from having very low environmental impact, solar-powered sites also have the advantage of being very lowmaintenance, with a technical lifetime of 20 years or so, and much more reliable than diesel generator-powered systems. Also, solar power scales with the load, so the size of the solar installation can be matched to actual needs without unnecessary capacity.

On the other side a micro-wind turbine can support a traditional RBS site without too large impact on cost, where on average a wind velocity is about $5 \mathrm{~m} / \mathrm{s}$. In most case a hybrid solution combining of solar and wind is the actually the most feasible solution for autonomous BTS site. Anyway the size of solar cell and wind turbine have to be defined based on BTS load and on-site availability solar and wind. In the paragraph 3.4 a typical hybrid solution for off-grid BTS is presented.

Finally fuel cells are increasingly being considered as a viable alternative site energy solution for telecoms. They can be deployed in place of diesel generators, and partly replace batteries, at remote sites with long back-up requirements. In addition to improving energy efficiency, they can also improve network up-time and reliability. Moreover environmental advantage in terms of special waste disposal will be obtained by using fuel cell in substitution of backup battery. 


\section{Telecommunications power systems and energy saving}

Energetic auditing of a BTS is the most important step in the understanding of energy management of wireless telecommunication power system. With this aim it has been realized a campaign of measurements for a radio-telecommunication apparatus starting from on-site measurements, performed in collaboration with Italian companies of mobile communications systems (Vodafone, H3G, Telecom and Wind), which take into account different technologies (GSM, UMTS, DCS+GSM+UMTS), different typologies of apparatuses (outdoor, room, shelter), different locations (North, Centre, South of Italy) and different working loads.

Thanks to the collaboration of the Italian mobile telecommunication providers, it has been possible to retrieve data coming from a statistic sample of around 100 radio base stations located on the whole national territory, that corresponds to more than 1000 monitoring days. All the field measurements are performed by using specific monitoring systems (Pizzuti, 2008).

For carrying out the statistic analyses and the correlations we considered separately the following characteristics of the systems:

- $\quad$ Systems typologies (Shelter, Room, Outdoor)

- $\quad$ Systems technologies (UMTS, GSM, DCS)

- $\quad$ Localization (North, Centre and South)

and the following functioning parameters:

- Energy consumption (Wh)

- Instantaneous Power (W)

- Internal temperature $\left({ }^{\circ} \mathrm{C}\right)$

- External temperature $\left({ }^{\circ} \mathrm{C}\right)$

- $\quad$ Phone traffic for cells (erlang)

A specific database has been built containing all data related to: energetic consumptions, BTS localization, typology and technologies, environmental parameters.

\subsection{Energetic consumptions associated to a radio base station}

Aim of our studies is to find statistic correlations between the energetic consumptions and the operational parameters of the BTS. Moreover we are interested to study both the energetic consumption correlated to the transmission function of the apparatuses and the energetic consumptions related to the cooling of the equipments and infrastructures. To achieve this goal, we made statistical analysis by using the software " $R$ " of the "RFoundation for Statistical Computing" R-foundation for statistical computing" (www.rproject.org/foundation/).

From these analysis one can establish the following:

$>$ The average yearly consumption of a BTS is ca. $35500 \mathrm{kWh}$ compatible with the average consumption of 10 Italian families. If we consider that in Italy there are 60.000 BTS (data 2007 coming from the NIR Observatory - ISPRA), the total average yearly consumption of all the BTS systems present in Italy is ca. 2,1 TWh/year; which is the $0,6 \%$ of the whole national electrical consumption (data source: TERNA 2007). In terms of economical and environmental impact, the data correspond to ca. 300M€ yearly energy costs and ca. 1,2 Mton of $\mathrm{CO}_{2 \text { eq }}$ emitted in the atmosphere every year. 
If we carry out analyses on the average energy consumptions associated to the different technologies, we will note that the GSM energy consumptions are considerably higher than the UMTS technology - as it is expected because of the different mode of operation of the two technologies (Table 1)

\begin{tabular}{|c|c|c|}
\hline \multicolumn{3}{|c|}{ Energy Consumption/technology } \\
\hline Technology & $\mathbf{k W h} /$ day & $\mathbf{k W h} /$ year \\
\hline UMTS & 72,97 & 26268 \\
\hline GSM & 111,35 & 40085 \\
\hline
\end{tabular}

Table 1. Energy consumption for GSM and UMTS technology

$>$ To evaluate the daily energy consumptions and the contributions due to the transmission and air-conditioning, in the following graph is represented the daily trend of the energy consumptions of a BTS. We can clearly distinguish two different trends: a constant energy consumption value of about $800 \mathrm{Wh}$ for the nighttime and the morning, and an oscillating trend, with an average value of about $1100 \mathrm{Wh}$ for the hottest hours and the late evening. This trend is comprehensible if we consider that in the first case the consumption is due only to the transmission functions (constant trend), whereas in the second case at the transmission functions are added the conditioning energy consumption, with a "saw tooth" trend generated by the switching on/off of the air-conditioning systems. We can therefore divide the energy consumptions in two contributions; i.e.: approx. $2 / 3$ of the consumed daily energy are due to the transmission, whereas $1 / 3$ of the energy is used for feeding the conditioning systems.

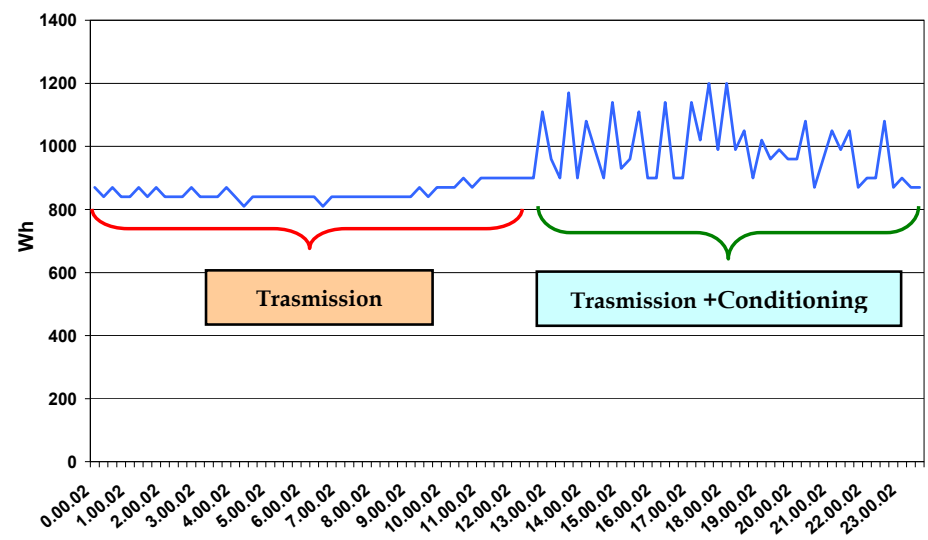

Fig. 3. Daily Energetic Consumption of a BTS 
In order to verify our latter statement in figure 4 we show the power distribution considering four selected days:

- $\quad$ 15th December 2007: it represents the coldest day during the monitoring period in which the internal temperature ranges from a minimum of $2,8^{\circ} \mathrm{C}$ to a maximum of $9,5^{\circ} \mathrm{C}$ (the blue line);

- 19th December 2007, it represents a typical day of the coldest period in which the temperature ranges from a minimum of $7,0^{\circ} \mathrm{C}$ to a maximum of $17,6^{\circ} \mathrm{C}$ (the violet line);

- 24th May 2008, it represents a typical day of the hottest period in which the temperature varies from a minimum of $15,5^{\circ} \mathrm{C}$ to a maximum of $37,3{ }^{\circ} \mathrm{C}$ (the green line);

- 27th May 2008, it represents the hottest day of the monitoring period in which the temperature ranges from a minimum of $21,8^{\circ} \mathrm{C}$ to a maximum of $42,5^{\circ} \mathrm{C}$ (the red line).

There is a clear difference among the distribution functions on the coldest days (blue and violet line), in which the instant power is presumably due only to the transmission function and show a peak in correspondence of defined power values, and the distribution functions on the warmest days (red and green lines), in which there are both the transmission and air conditioning contributions .

In this way we can esteem an energetic consumption connected to the transmission functions and another connected to the air-conditioning functions which are $2 / 3$ and $1 / 3$ of the total energetic consumption, respectively.

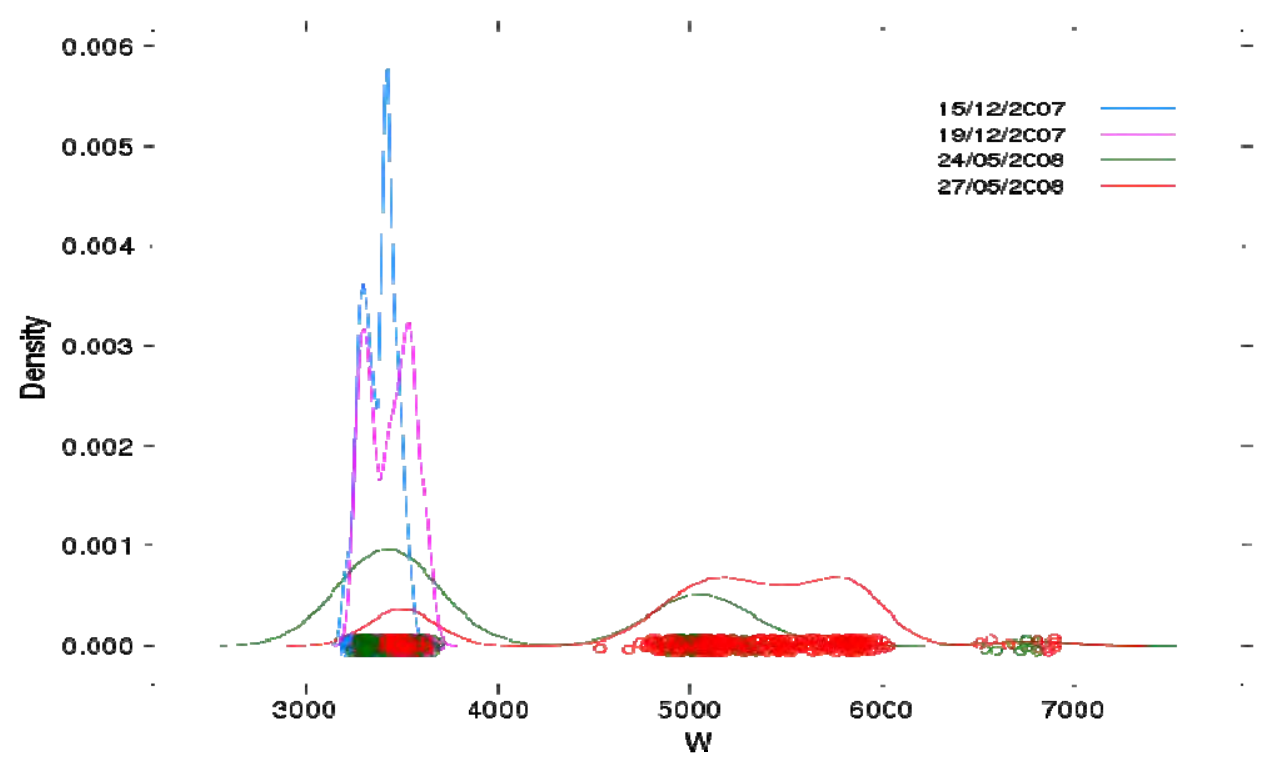

Fig. 4. Density of states plotted as a function of power distribution 
In figure 5 we plot the variation of the energetic consumptions versus the external temperature, for different BTS typology (shelter, room, outdoor) and BTS technology (UMTS and GSM).

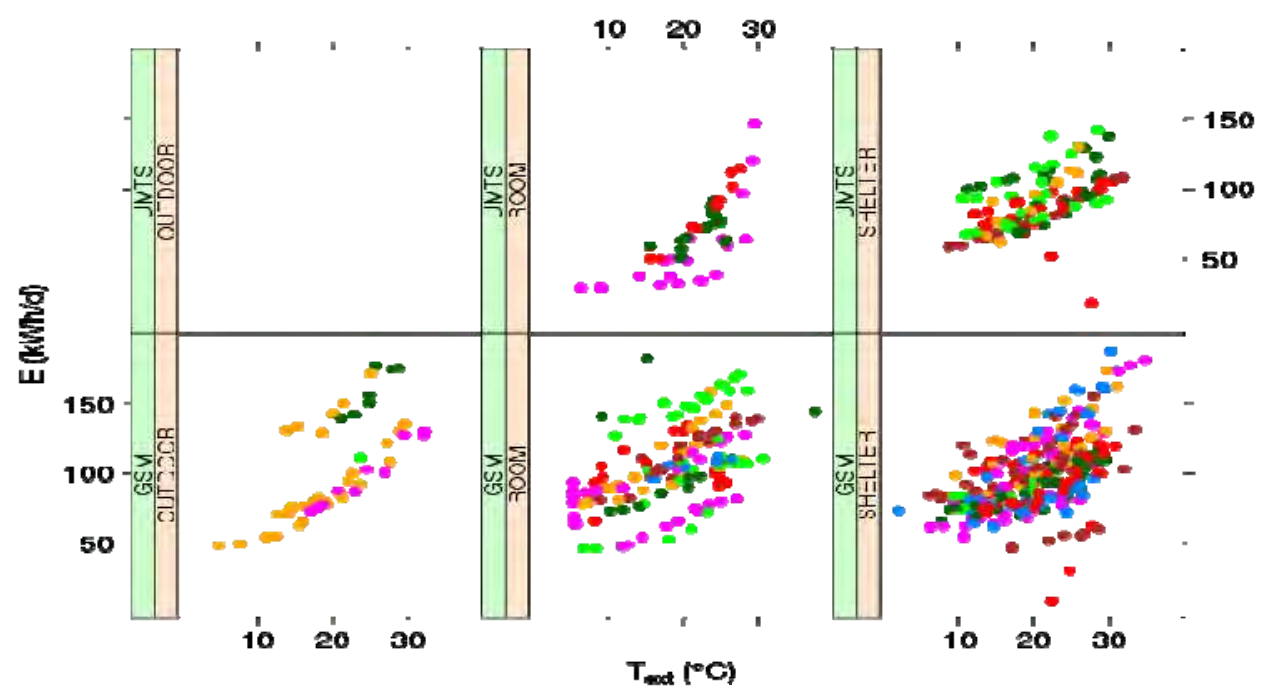

Fig. 5. Energetic Consumption versus external temperature

A "universal trend" of the energy consumption versus the temperature is discovered independently both from the technology used and from the typology of BTS. Furthermore the higher dispersion of the consumption data in the room and shelter typologies, in comparison with the outdoor one, can be comprehensible if we consider that in the first two cases there is a higher thermal dispersion - with a consequent increase of the consumptions - which is needed to air-condition the equipments as well as the environment where they are implemented.

In figure 6 we plot the energy consumptions as a function of a different time of the year, for different BTS technology (GSM and UMTS) and BTS typology of site (outdoor, room, shelter). First of all we find a similar behaviour during the months with a greater energetic consumption in summer respect to the winter, as expected. 


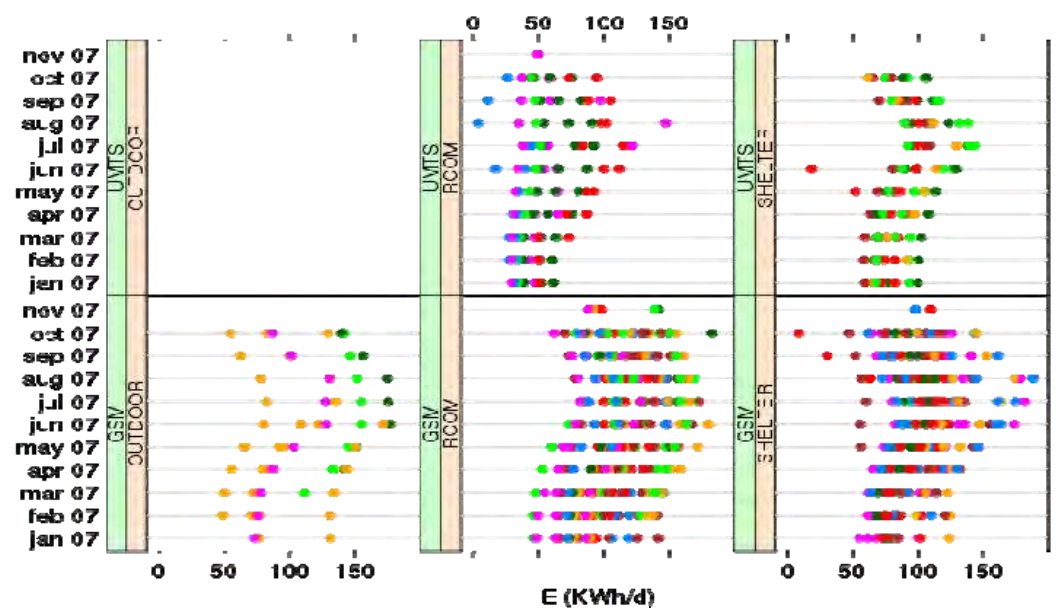

Fig. 6. Energetic consumptions versus. time of the year

Moreover comparing the graphs for the room and shelter typology, it is clear that the UMTS technology has on average lower energetic consumption of GSM technology, because of the different characteristic of the mobile communication standards. No difference was found for energetic consumptions versus the time of year for the three BTS typologies.

For understanding an eventual correlation between the energy consumptions data and the numbers of phone calls of a BTS, we show in figure 7, the energy consumptions as a function of call traffic (in erlang). There seems to be no correlation between these two parameters; that means that at the moment any intervention which may regulate BTS turning on/off when the call traffic goes down, is realized.

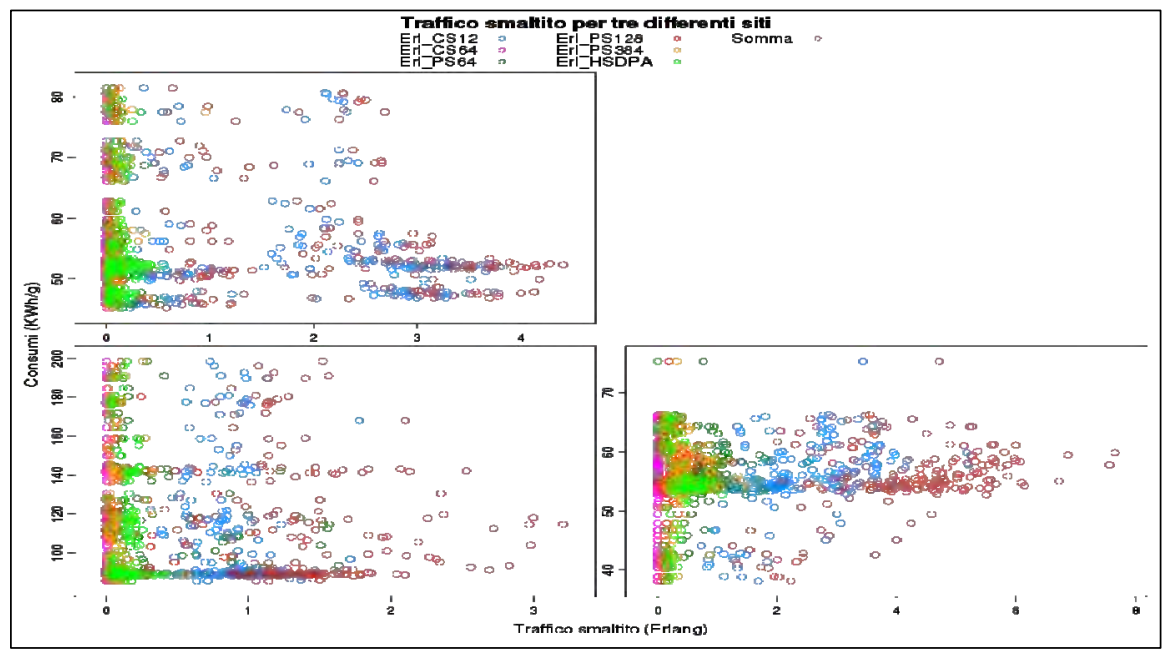

Fig. 7. Energy consumption vs traffic for three different sites 


\subsection{Energy saving}

Starting from the statistical analyses on the BTS energy consumptions, it is useful to study the possible interventions for optimizing and saving energy consumptions. Our aim is to individuate useful interventions both for saving action on conditioning systems and on transmission consumption.

Regarding the saving of energy consumptions relevant to the air-conditioning we studied two possible intervention strategies; the first one was based on "intelligent" algorithms for the optimization and dynamical regulation of the air-conditioning functions, the second one was founded on the local cooling of the single electronic equipment, avoiding to aircondition the environment where they were located. Both hypotheses were based on the fact that inside the shelter the thermo-dynamic parameters (temperatures, humidity, etc.) can assume values ranges larger than in areas frequented by people. Therefore both the use of air-conditioning intelligent systems and the local cooling technologies are useful strategies for saving energy, basing on the possibility to eliminate useless conditioning actions of the environment and mechanical parts. One can estimate that such interventions can achieve an energy saving from $5 \%$ to $10 \%$ of the air-conditioning consumptions.

For optimizing the consumptions coming from the transmission functions we studied and tested a software feature launched by Ericsson that helps to use the BTS-GSM transmission power in a more efficient way (Hjorth, 2008). These algorithms can correlate the phone traffic of a BTS and the energy consumptions. During periods of low network traffic, the feature effectively puts transceivers that are not being used in standby mode - overcoming the traditional practice of having radio equipment continually turned on, which results in energy being wasted.

Depending on the network traffic pattern, the feature algorithm parameter settings and on the type of apparatus, this innovation can save between 5 and 20 percent of the energy per BTS when a base station is in use, while still providing the same services and quality to end users.

The study has been carried out with a two fold approach:

- The direct investigation of test BTS in order to have direct hints about the feasibility of the project, the practical problems, and the real savings. To reach this goal on field measurements have been carried out in an operating BTS during periods in which the feature was either activated or not activated.

- However, it is not feasible and practically unreliable to explore all the BTS power consumption and to measure the power saved with different configurations of the feature algorithm. Thus a simulation study has been carried out. The best parameters ensuring good communications and best savings have been pointed out.

A comparison between on field measurements and simulations have been realized, in order to optimize the parameters used in the "BTS power saving algorithms".

Parameters useful in this kind of analysis are telephone traffic, BTS typology and location, number of transmitters. Measurements of energetic consumptions and other environmental parameters have been realized in a suburban BTS (provider Telecom Italia Mobile) located in Agliana (Toscana), composed by 3 GSM transmitter and 3 DCS transmitter. On this BTS the "power saving" function has been activated as experimental on field test of "power saving algorithms" 


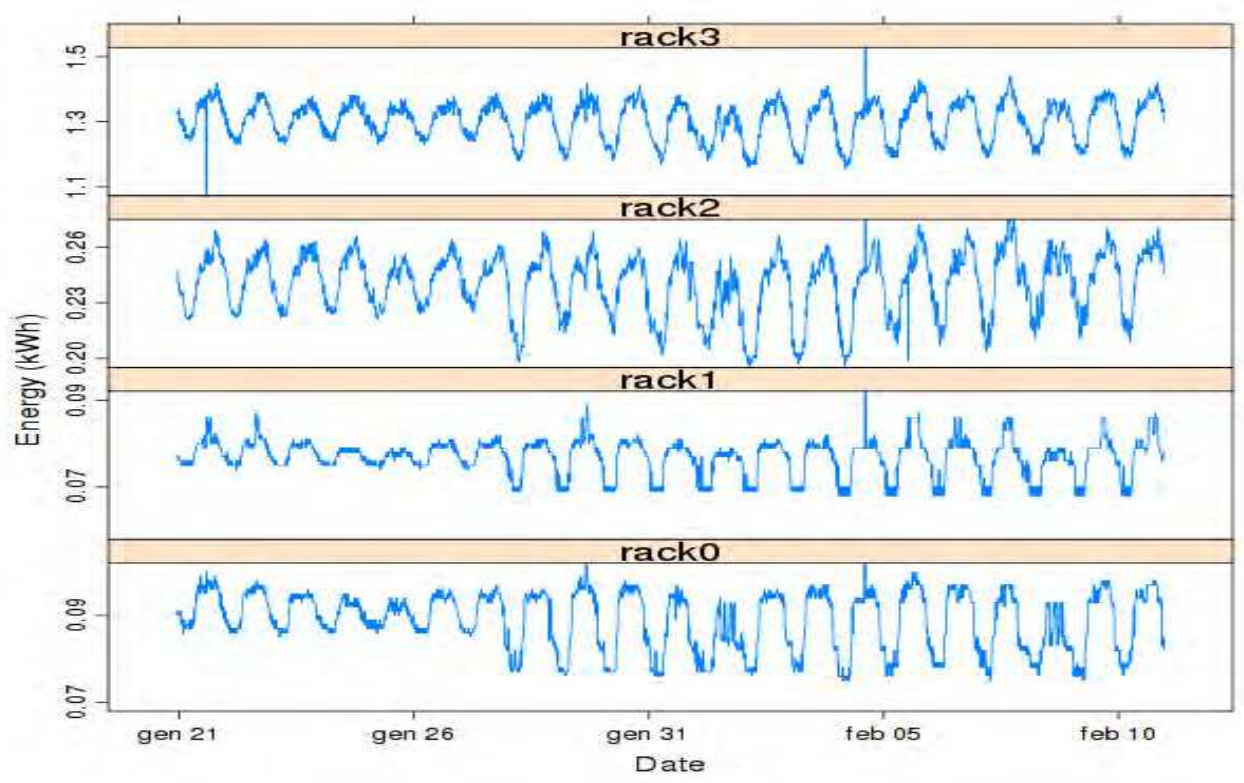

Fig. 8. BTS energetic consumption at the experimental site - Agliana

The results obtained by our monitoring are presented in the following figure 8 , where we reported the energy consumption of the basic radio station for three weeks; in two of those

was activated the "Power Saving" function. Rack 0-Rack 2 represents the energy consumption of each DCS transmitter, Rack3 shows the energy consumption of all GSM transmitters. It is clear that average value of energetic consumptions are lower in the days in which the power saving function is active: a decrease of more than $10 \%$ of energetic consumption is evident starting from the second period.

In the following graph (figure 9) it is presented the measured energy in the same day of the week (Thursday), in the condition of power saving function ON (red line) and OFF (blue line).

The considerable energy saving achieved during the nighttime - when the call traffic goes down and the "power saving" algorithm can switch off many transmission supporters - is here very remarkable. On the contrary, during the daytime, the curves trend coincides, since the high traffic does not allow the switch off of any transmitters. 


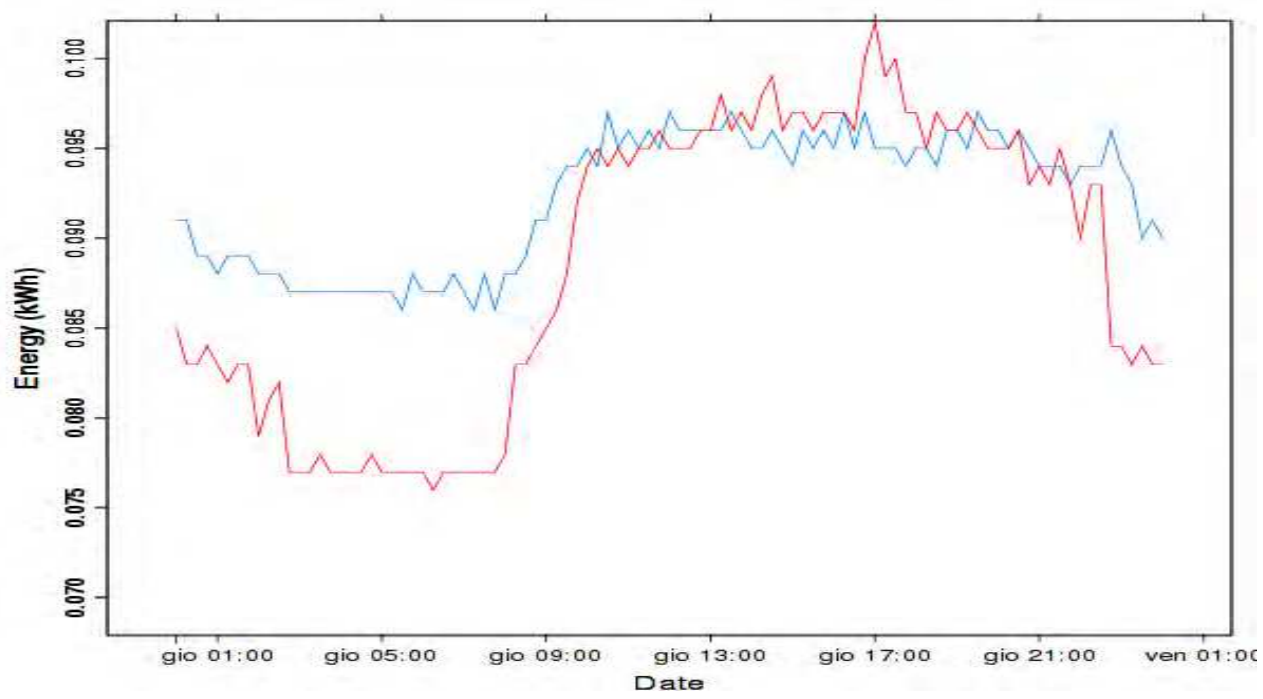

Fig. 9. Comparison of the measured daily energetic consumption in a day with Power Saving ON (red line) and OFF (blue line).

The data of the experimental measures have been compared to the simulation analyses realized through a specific software which has been implemented (Lubritto,2009).

The simulation software takes as input the available measured data (average number of telephone calls started every ten seconds, the average length of calls, the cell parameters, the parameters of the Power Savings algorithm) then it uses a Montecarlo algorithm for simulation of telephone traffic.

The number of calls started every 10 seconds is supposed to follow a Poisson distribution with a varying average value during the day. Length of calls follow an exponential distribution with a given average. Both average values, measured every hour, are taken from the collected data. The convolution of the two distributions gives the number of active calls for any given time. However, the maximum number of calls in the cell is fixed by the number of channel available. 


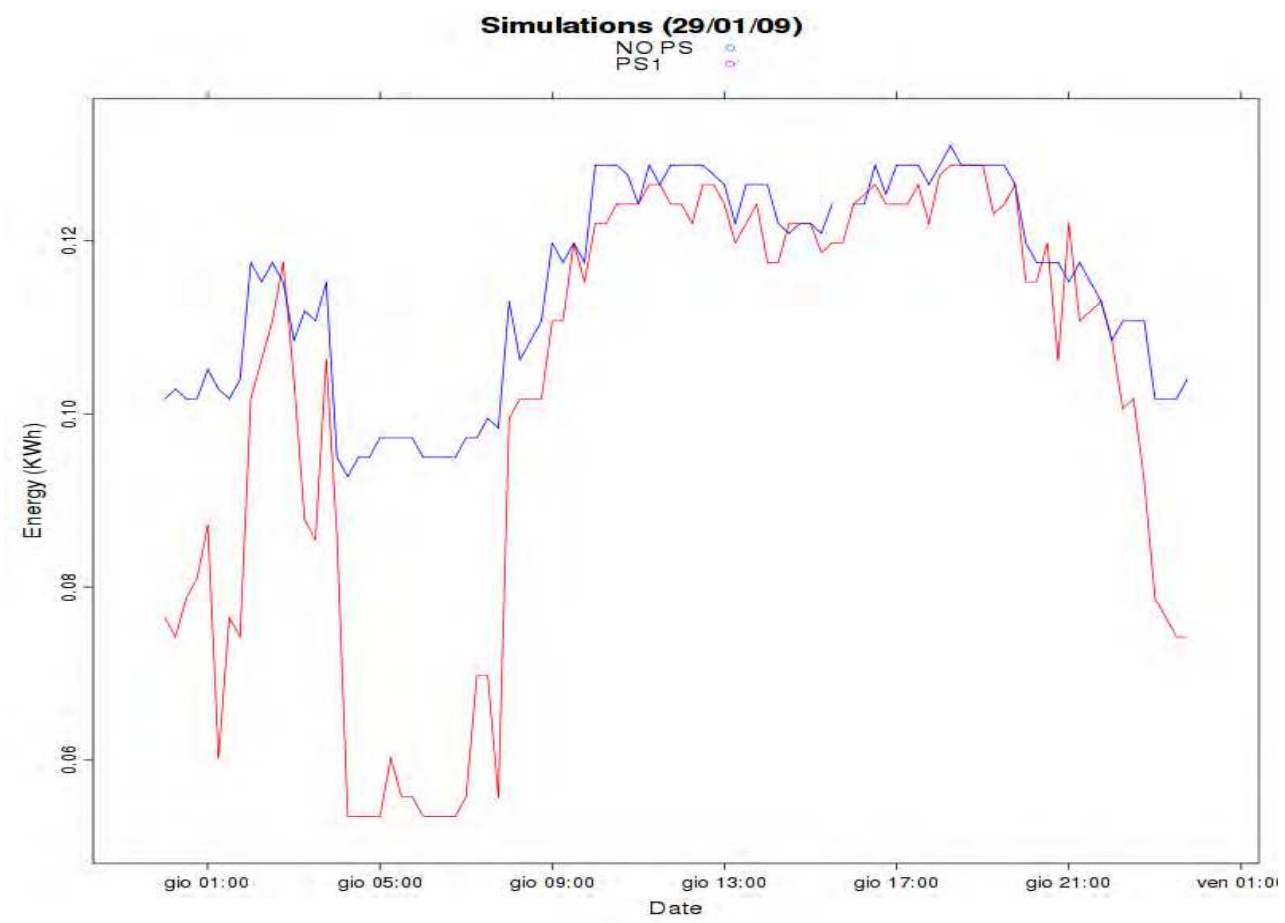

Fig. 10. Comparison of the simulated energy consumption in a day - with (red line) and without (blue line) Power Saving features on.

In the above figure 10 we reported the values obtained by the simulation in a day; the blue lines indicate the consumptions without Power Saving and the red lines indicate the activation of the Power Saving. As it is evident, the simulation software faithfully reproduces the data achieved by the field measurements.

The similarity with on field measurements is acceptable: here too the savings are evident in periods of low traffic when there is the possibility to switch off the unused channels, as for the measured data.

After established the goodness of the simulation algorithm, we can analyze the Power Savings optimization parameters. In such a way we address the set of parameters giving the maximum power saving, and thus lower environmental impact, while still guaranteeing the communication quality.

The study has to be carried out with the following criteria:

[1] the intervals were chosen to cover the entire space of the suggested parameters;

[2] for each set of parameters were we took an average of many runs;

The resulting optimal set of parameters depends on the average communication load and available channels, so should be site specific or at least cover "classes" of sites, with similar load and operating behaviour. Optimal parameter sets for the sites under survey have already been created, and an improvement in energy saving of about of $3 \%$ is expected. 
The saving obtained through the introduction of the "Power Saving" algorithms might change from $10 \%$ up to $15 \%$ of the transmission consumptions, according to the typology and the location of the basic radio station. With the same algorithm we succeeded in obtaining the Power Saving parameters set that maximizes the energy saving, increasing it of a further $3 \%$.

In conclusion, if we sum up the contributions of the energy saving to the air-conditioning functions and the transmission functions, - considering the feedback processes of the two components - we obtain a total yearly energy saving of $20 \%$ of the total consumptions (i.e. $7000 \mathrm{KWh}$ per year) with an economical advantage of approximately $1000 €$ /year saved for each BTS, that means a further environmental advantage in avoiding to emit, for each year and BTS, 4 Ton of $\mathrm{CO}_{2 \mathrm{eq}}$ in the atmosphere.

\section{Telecommunications power systems and renewable energy}

In order to introduce clean technology in the telecommunications power system management, one has to consider the use of renewable sources technologies (photovoltaic, wind, hybrid systems) installed on telecommunication systems infrastructures. We analyzed the most advanced technological solutions in the photovoltaic sector (single crystal, multicrystal panels, amorphous silicon, thin films) and in the further renewable sources, useful for producing the energy in situ in consideration of the functioning conditions and the structural features of a radio-telecommunication station.

We chose to analyze the interventions in locations with different testing conditions for each provider, in order to plan and realize photovoltaic systems for basic radio stations in urban and rural areas (raw-land), to forecast the use of combustible cells for substituting the batteries of a microcell site and to analyze the use of different renewable sources for grid-off BTS (not connected to the electrical net), fed by generators

Therefore it has been realized an experiment in which use of photovoltaic systems and other renewable sources for different typologies of contexts (urban and rural areas) and for apparatuses not reached by the electricity network (stand-alone apparatuses), has been tested.

Two rural sites in which a photovoltaic plant has been built in with provider Vodafone, in order to understand how to use infrastructure of the BTS to obtain a total or partial architectural integration of the photovoltaic plants on the shelter o support pole. It has been shown that their energetic productivity depend on the geographical location, on the surface available to implement the photovoltaic plants and on the effects of shadow.

In two of these pilot sites, photovoltaic plants have been realized both on shelter and on the infrastructures; the area of PV modules varies from 16 to $20 \mathrm{~m}^{2}$, limited by the available site space, to guarantee a production of 2.0 and 2,5 kWp. Figures 11 and 12 show the installation on the two sites. 


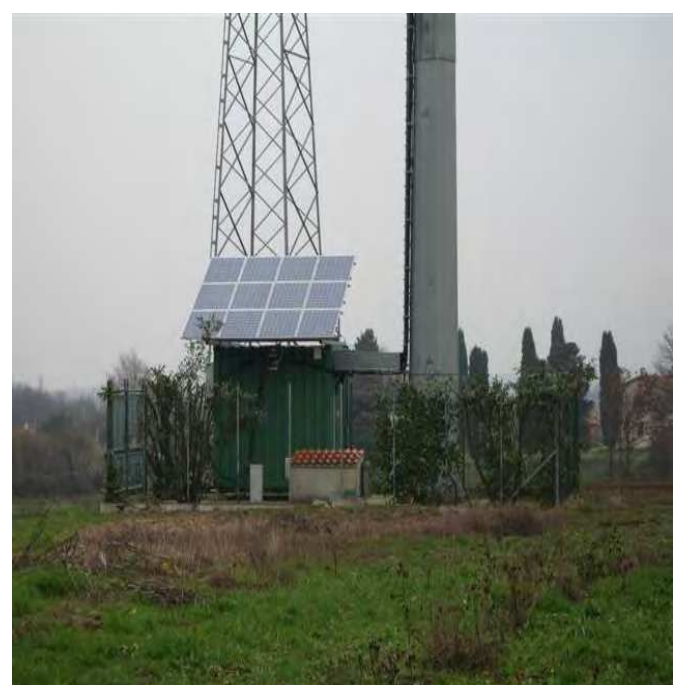

Fig. 11. Photovoltaic system installed on the BTS infrastructure (Vodafone)

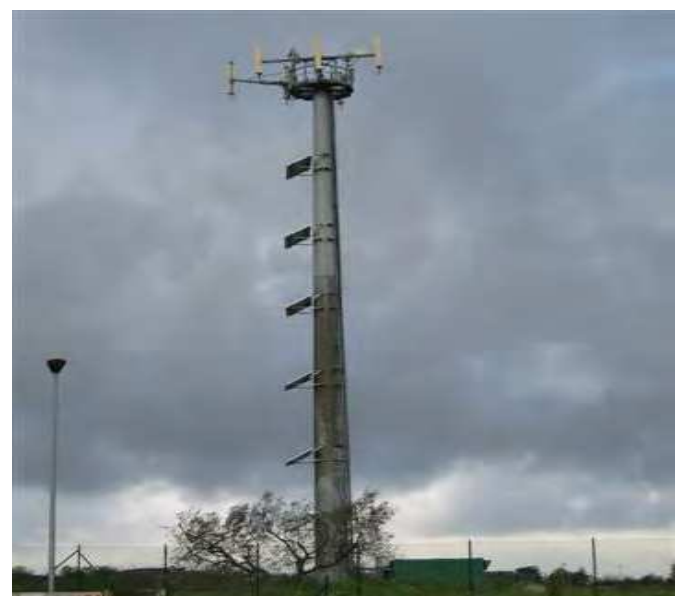

Fig. 12. Photovoltaic system installed on the BTS infrastructure (Vodafone)

These sites came into operation on $01 / 01 / 2008$ and, according to data provided by VODAFONE the two photovoltaic systems have produced, up to $30 / 05 / 2008$, respectively 1100 and $1200 \mathrm{kWh}$; this implies an annual estimated production of 2640 and $2880 \mathrm{kWh}$. A further important element of the application - made by the involved provider - was to activate and complete the whole proceeding in order to obtain incentivizing by Italian electricity Authority (i.e. "Conto Energia" fund). It is to be noted that such an application gives an environment advantage of approximately of 3 Ton of not emitted $\mathrm{CO}_{2 e q}$ /year for each BTS, apart all reduction of the pollution coming from furter physical agents.

In order to carry out specific controls on these pilot sites and to be able to compare the conditions of energetic consumption pre and post installation of the photovoltaic panels, a 
monitoring station has been used that allows to check operational parameters such as electric consumption, external and inside temperature and other environmental parameters. On these same sites we studied further technological solutions in the photovoltaic field. In particular very important is to evaluate the possibility to implement further photovoltaic technologies (amorphous, thin film) and to evaluate the technical feasibility and the investment advantage for each solution.

A very convenient and realistic solution - from the technical and commercial point of view apart from the use of single and multi crystal panels - is the usage of panels based on the amorphous and thin film.

In the amorphous solution one can consider an efficiency of about half of the crystalline, well compensated by an implementing cost of $70 \%$ less than the crystalline solution. Using the aforementioned option we get a 6 years payback time.

In the case of the thin film solution, we have to consider a reduction of efficiency of approx. $10 \%$ less than the amorphous solution. Furthermore the considered (sub-vertical) exposure affects the energy production reducing it of the $30 \%$. Beside this negativity, we noticed a net gain in the installation costs, which is ca. $55 \%$ higher than the crystalline solution. Finally, we could calculate the GSE government incentive basing on a system architectonically integrated. With these hypotheses there would be 6 years payback time.

In general, in order to implement photovoltaic energy systems for feeding radio base stations in a total or in a partial way in urban areas one have to take into account the presence of obstacles which could cause shadowing effects and the real presence of useful areas.

A very interesting application of renewable energy source with telecommunication systems sector is the situation when BTS is located far from the electrical network (grid-off systems). In order to analyze innovative technologic solutions for producing energy close to the BTS, we used as experimental site the BTS located in Sardinia on Gardaininu Mount (Nuoro, provider TIM), for which to completely fulfill the BTS energetic requirements (approx. 35500 $\mathrm{kWh}$ a year), we considered to implement a micro-wind system (overhead generators with an energy power up to $20 \mathrm{~kW}$ ) coupled to a $4.5 \mathrm{~kW}$ photovoltaic system. Therefore it is convenient to implement an hybrid solution composed by :

- a photovoltaic system with panels mounted on a support between the transmission tower and the south side of the external border, since we noticed an available surface of ca. $50 \mathrm{~m}^{2}$ was present;

- a micro-Wind system (power of $20 \mathrm{~kW}$ ), for which one can estimate energy production starting from wind average speed and hours of productivity in the specific site;

In the aforementioned site in Sardinia, the annual average speed of the wind is $5 \mathrm{~m} / \mathrm{s}$ (CESI Wind Atlantis,2007) and the annual productivity is 2000 hours. Consequently electric energy power production is $31567 \mathrm{kWh}$, and, the payback time is little more than 5 years.

\section{Telecommunications power systems and environmental monitoring}

In the framework considered in the present chapter, it becomes very important to study the relation between energetic aspect, environmental impacts and radio-telecommunication power systems.

One can consider at least three different relevant contexts:

- Impact of BTS on the landscape

- Electromagnetic pollution generated by the BTS 
- Environmental impact coming from further polluting agents (emission of greenhouse gases, noise, etc.)

Regarding the impact on the environment, it is fundamental to build BTS integrated in their territorial context. The possibility to use the structures of the plants (support poles, shelter, etc.) in order to realize energy production systems deriving from renewable sources could be an useful way to satisfy such request. It is evident that up to now such problems have not been faced, but we believe it essential to define the right prescriptions in order to minimize the impact of the BTS on the environment and, at the same time, to implement innovative power energy solutions.

Besides, the possibility to decrease the emission quantity of the greenhouse gases deriving from the BTS functioning is strictly joined to the introduction of the distributed production system of renewable energy. In fact, the use of solutions based on renewable energy, especially in grid-off conditions, can considerably reduce the impact on the environment caused by the station and the feeding generators management. The usage of a micro-wind or photovoltaic systems may avoid the implementing of feeding systems - which should be fed with fuel every day with the relevant high use of vehicles. That would mean a remarkable reduction of the emissions in the atmosphere.

Even more important is the impact on the environment and on the population of the electromagnetic fields generated by the transmission systems. Especially during last years, such a problem has attracted the attention of single citizens and of the entire civil community, because of the considerable diffusion on the territory of low frequency electromagnetic fields sources (power lines) and of high frequency sources (radio-television stations and mobile phone stations). From a technical point of view, we should note that the field level in an area can considerably change according to the status of the existing transmitters, to the emitted power (at its turn variable according to the users' need) and to the further territorial characteristics, such as the presence of buildings and/or other obstacles which determine reflections/refractions changeable in time. Basing on these premises and considering the hypothesized energy power saving strategies, we evaluated the feedback on the minimization of the electromagnetic fields emitted by the BTS. It is easy to understand that the use of a "power saving" system can give a valid contribution to the reduction of the BTS emissions. In fact, switching off the transmitters when the traffic goes down, means to get a null emission of the electromagnetic fields and a reduction of the daily average value emitted by the radio base stations. If we consider that, following to the activation of the "power saving" algorithm there is a switch off of $70 \%$ of transmitters during nighttime (from 24 to 8), we can estimate a daily average reduction of the electromagnetic emissions of $15-20 \%$.

\section{Acknowledgments}

I would like to thank my colleagues and collaborator (in no particular order)- Salvatore Curcuruto, Antonio D'Onofrio, Antonio Petraglia, Carmela Vetromile, Maria Logorelli, Giuseppe Marsico, Floriana Caterina, Laura Miglio - for fruitful discussions and for the many hours of working together on research project. This research project has been funded by ISPRA. 


\section{References}

Boccaletti C.; Fabbri G. \& Santini E. (2007). Innovative Solutions for Stand Alone System Powering, Proceedings of INTELEC, pp. 294-301, 978-1-4244-1628-8, Rome (Italy), September 2007, IEEE, Rome

Efraimsson L. (2008). Halve the Power Related Costs for a Cluster of Diesel - Fed Telecom Sites, Proceedings of INTELEC, pp. 397-400, 978-1-4244-2056-8, San Diego (CA), September 2008, IEEE, San Diego

Hjorth P. ; Lovehagen N. , Malmodin J. \& Westergren K. (2008). Reducing $\mathrm{CO}_{2}$ Emissions from Mobile Communications - BTS Power Savings and Tower Tube, Ericsson Review n. 1,

Ikebe H. ; Yamashita N. \& Nishii R. (2007). Green Energy for Telecommunications, Proceedings of INTELEC, pp. 750-755, 978-1-4244-1628-8, Rome (Italy), September 2007, IEEE, Rome

IPCC, Fourth Assessment Report (AR4) Climate Change 2007 - International Panel of climate Change, 2007

ISPRA, Non Ionizing Database - Italian Agency for Environmental Protection, 2007

Louhi J. T. (2007). Energy Efficiency of Modern Cellular Base Stations, Proceedings of INTELEC, pp. 475-476, 978-1-4244-1628-8, Rome (Italy), September 2007, IEEE, Rome

C. Lubritto, A. Petraglia, C. Vetromile, F. Caterina, A. D'Onofrio, M. Logorelli, G. Marsico, S. Curcuruto "New Energy" for Telecommunications Power System in Proceedings of INTELEC, pp. 443-445, 978-1-4244-1628-8, Rome (Italy), September 2007, IEEE, Rome

C. Lubritto, A. Petraglia, C. Vetromile, F. Caterina, A. D'Onofrio, M. Logorelli, G. Marsico, S. Curcuruto "Telecommunications power systems: energy saving, renewable sources and environmental monitoring"- in Telecommunications Networks, Proceedings of INTELEC, pp. 120-126, 978-1-4244-2056-8, San Diego (CA), September 2008, IEEE, San Diego.

C. Lubritto, A. Petraglia, C. Vetromile, F. Caterina, A. D'Onofrio, M. Logorelli, G. Marsico, S. Curcuruto, L. Miglio, F. Cenci "Simulation analysis and test study of BTS power saving techniques" - Extended Abstract INTELEC 2009 - 18-22 /October/2009 Incheon South Corea.

Masone M. (2007). Environmental Certification for Service Networks and Data Centers, Proceedings of INTELEC, pp. 756-759, 978-1-4244-1628-8, Rome (Italy), September 2007, IEEE, Rome

Morea F. ; Viciguerra G. , Cucchi D. \&Valencia C. (2007). Life Cicle Cost Evaluation of Off-Grid PV-Wind Hybrid Power Systems, Proceedings of INTELEC, pp. 439-441, 978-1-42441628-8, Rome (Italy), September 2007, IEEE, Rome

Pizzuti F. ; Rega G. \& Grossoni M. (2008). Site Power Saving, Proceedings of INTELEC, pp. 8489, 978-1-4244-2056-8, San Diego (CA), September 2008, IEEE, San Diego.

Roy S. N. (2008). Energy Logic: A Road Map to Reducing Energy Consumption in Telecommunications Networks, Proceedings of INTELEC, pp. 90-98, 978-1-4244-2056-8, San Diego (CA), September 2008, IEEE, San Diego

White Paper Ericsson (2007). Sustainable Energy Use in Mobile Communications White Paper EAB-07:021801 Ericsson AB 2007. 


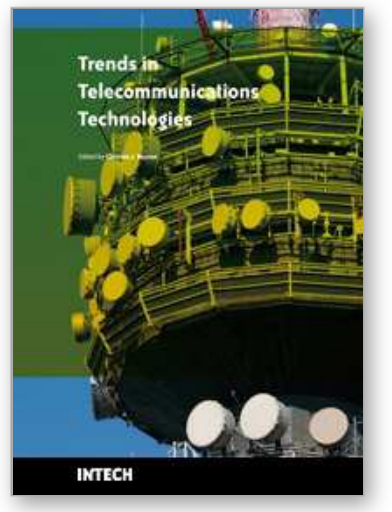

\author{
Trends in Telecommunications Technologies \\ Edited by Christos J Bouras
}

ISBN 978-953-307-072-8

Hard cover, 768 pages

Publisher InTech

Published online 01, March, 2010

Published in print edition March, 2010

The main focus of the book is the advances in telecommunications modeling, policy, and technology. In particular, several chapters of the book deal with low-level network layers and present issues in optical communication technology and optical networks, including the deployment of optical hardware devices and the design of optical network architecture. Wireless networking is also covered, with a focus on WiFi and WiMAX technologies. The book also contains chapters that deal with transport issues, and namely protocols and policies for efficient and guaranteed transmission characteristics while transferring demanding data applications such as video. Finally, the book includes chapters that focus on the delivery of applications through common telecommunication channels such as the earth atmosphere. This book is useful for researchers working in the telecommunications field, in order to read a compact gathering of some of the latest efforts in related areas. It is also useful for educators that wish to get an up-to-date glimpse of telecommunications research and present it in an easily understandable and concise way. It is finally suitable for the engineers and other interested people that would benefit from an overview of ideas, experiments, algorithms and techniques that are presented throughout the book.

\title{
How to reference
}

In order to correctly reference this scholarly work, feel free to copy and paste the following:

Carmine Lubritto (2010). Telecommunication Power System: Energy Saving, Renewable Sources and Environmental Monitoring, Trends in Telecommunications Technologies, Christos J Bouras (Ed.), ISBN: 978953-307-072-8, InTech, Available from: http://www.intechopen.com/books/trends-in-telecommunicationstechnologies/telecommunication-power-system-energy-saving-renewable-sources-and-environmentalmonitoring

\section{INTECH}

open science | open minds

\author{
InTech Europe \\ University Campus STeP Ri \\ Slavka Krautzeka 83/A \\ 51000 Rijeka, Croatia \\ Phone: +385 (51) 770447 \\ Fax: +385 (51) 686166 \\ www.intechopen.com
}

\author{
InTech China \\ Unit 405, Office Block, Hotel Equatorial Shanghai \\ No.65, Yan An Road (West), Shanghai, 200040, China \\ 中国上海市延安西路65号上海国际贵都大饭店办公楼 405 单元 \\ Phone: +86-21-62489820 \\ Fax: +86-21-62489821
}


(C) 2010 The Author(s). Licensee IntechOpen. This chapter is distributed under the terms of the Creative Commons Attribution-NonCommercialShareAlike-3.0 License, which permits use, distribution and reproduction for non-commercial purposes, provided the original is properly cited and derivative works building on this content are distributed under the same license. 